\title{
Application of fuzzy TOPSIS and generalized Choquet integral methods to select the best supplier
}

\author{
Aytac Yildiz ${ }^{a^{*}}$ and A. Yesim Yayla
}

${ }^{a}$ Faculty of Technology, Automotive Engineering Department, Amasya University, Amasya, Turkey ${ }^{b}$ Mechanical Engineering Department, Faculty of Technology, Marmara University, Goztepe-Istanbul, Turkey

\begin{tabular}{|c|c|}
\hline C H R O N I C L E & A B S T RACT \\
\hline $\begin{array}{l}\text { Article history: } \\
\text { Received June } 25,2016 \\
\text { Received in revised format: } \\
\text { October 22, } 2016 \\
\text { Accepted November } 1,2016 \\
\text { Available online } \\
\text { November } 42016 \\
\text { Keywords: }\end{array}$ & $\begin{array}{l}\text { Supplier selection is a complex multi-criteria decision making (MCDM) problem. There are } \\
\text { literally various methods for choosing appropriate supplier but there are several criteria } \\
\text { involved in complex decision making process. The classical MCDM methods cannot } \\
\text { effectively solve real-world problems however fuzzy MCDM methods facilitate the solution } \\
\text { fairly and enable the decision-makers to reach accurate decisions in this selection process. In } \\
\text { this study, a supplier selection problem is handled, in a firm in automotive industry of Turkey. } \\
\text { Fuzzy TOPSIS (Technique for Order Performance by Similarity to Ideal Solution) and }\end{array}$ \\
\hline
\end{tabular}

Fuzzy TOPSIS

Generalized Choquet integral

Turkish automotive industry

\section{Introduction}

In recent times, many innovations, improvements, and changes have been occurred in the industry. This is mainly due to the increasing customer demands, technological opportunities and innovations. The customers' needs have been enlarged depending on the technological changes; they have begun to demand lower prices and higher quality products at the same time. Heavy market competitions have occurred in many countries together with the new developments, the organizations have been obliged to meet customer demands with new products and services, and to collaborate with new suppliers in parallel of this (Tam \& Tummala, 2001).

Supply chain management, allows us to make decisions based on the information during the supply chain from supply of the raw material up to the manufacturing and distribution of processed products

* Corresponding author

E-mail address: aytac.yildiz@amasya.edu.tr (A. Yildiz)

(C) 2017 Growing Science Ltd. All rights reserved. doi: 10.5267/j.ds1.2016.11.001 
to the customers (Metz, 1998; Childerhouse et al., 2013). For the best usage of supply chain management; the total of current sources in hand at the supply chain should be used in the most appropriate manner in order to both make the information flow most effective all along the chain and also to fulfill the purposes related to the consumer service levels (Metz, 1998). A successful supplier selection process has become necessary for a successful supply chain management. Which one or which ones of them to be worked between prospective suppliers plays essential role to reach intended objectives (Liu \& Hai, 2005). The selection of supplier may be described as a determination procedure of purchasing the raw material, semi-finished products and materials needed for manufacturing in what quantity and which periods and from which supplier (Ghodsypour \& O`Brien, 1998; Benyoucef et al., 2003). While a wrong selection is enough to turn upside down of financial and operational status of the company (Araz \& Ozkarahan, 2007; Faez et al., 2006), selecting the best supplier can affect enormously the decreasing purchase costs and increasing competitive power (Faez et al., 2006; Hong \& Lee, 2013). Therefore activities of procurement departments and selection of suppliers in these activities have specific importance on the way towards this success of reducing costs (Muralidharan et al., 2002).

There are many criteria and sub criteria for measuring the performance of the supplier as well as specified main criteria. In this context, supplier selection problem is a multi- criteria problem necessitates evaluation of measurable and immeasurable various criteria together (Ghodsypour \& O'Brien, 1998; Byun et al., 2014). The firms are confronted with three major concepts in order to have larger shares in the market and protect their competitiveness. Those are "quality", "price" and "time". It is known that while the quality of product rises, the customer's ability to make payments is challenged or able to make a little more payments. Similarly timely delivery and production speed are important matters for the customer. When all of them are considered, the firms deem necessary for the better planning of their activities and organization structures. Suppliers have their own weaknesses and strengths. This situation involves the firms performing the most careful evaluation. If the suppliers are evaluated in a good way, there will not be any obligation to work with more than one supplier and this situation facilitates the development of long term partnerships. Long term partnerships, also brings obtaining low cost and high quality raw materials along with itself (Soner \& Onut, 2006). In a real situation, many input information are not known accurately for selection of a supplier. At the point of determination, values of many criteria and restrictions are indicated with uncertain terms such as "fairly high at quality" or "low at price". The deterministic models cannot easily include this uncertainty into the calculation. In the decision-making, if especially there is fuzziness and uncertainty with high degrees, the fuzzy set theory is one of the best means deal with the uncertainty of decision parameters. Fuzzy set theories, depending on the uncertainty, is used at supplier selection problems for transforming uncertain information in purposes and restrictions into fuzzy target, fuzzy restrictions (Amid et al., 2006). Utilizing MCDM methods operations decision-making transactions rather easier for the supplier selection which involves much more interaction especially among uncertainty and decision criteria. These firms want to select the best one among the suppliers which supplies these products as far as possible, due to a number of products being pretty much purchased by major firms in the automotive industry. It is also important to deliver products in a timely, reliable and quality manner as well as highquality and low cost desired by enterprises for the products especially procured from abroad. For that reason selection process of supplier firms doing business abroad is thought as a more critical process.

In this study, fuzzy TOPSIS and generalized Choquet integral among the MCDM methods are used according to supplier selection model based on literature review were presented in detail in Table 1 and by considering the opinions of three expert decision makers (DMs) working in the purchasing department of the firm, while the process of selecting the best one among alternative suppliers which supply the steering gear box product imported from South Korea and used in vehicles manufactured by firm operating in an automotive industry in Turkey. The aim here is, to help by offering more detailed solution information and under more accurate and reliable conditions, during the key supplier selection process, to DMs through comparing the results obtained by solving via two different MCDM methods of the problem dealt with. 
The rest of this paper is organized as follows. In section 2, a brief literature review on the supplier selection methods and criteria in automotive industry is described. In section 3, fuzzy TOPSIS and in section 4 generalized Choquet integral methods are explained briefly. In section 5, a brief information about the case study is given, fuzzy TOPSIS method in solving the supplier selection problem is applied and generalized Choquet integral method in solving the supplier selection problem is applied. In section 6 application results of the methods are compared. The conclusions are discussed in section 7.

\section{Literature review}

Maintaining a long-term partnership with suppliers and selecting the most reliable suppliers, is one of the most important decisions of supply chain management nowadays. Therefore, using convenient methods in selection process due to selection of correct supplier depends on a wide range includes quantitative and qualitative factors rather than screening a set of price list (Ho et al., 2010). In spite of a lot of methods have been offered and used for selecting and evaluating the suppliers; most of them is to try listing suppliers from the best to the worst or selecting the best one among them (Araz \& Ozkarahan, 2007). Categorical methods, data enveloping analyze (DEA), clustering analyze (CA), case-based reasoning systems may be given as examples for the decision methods used for supplier pre-evaluation, nevertheless, these methods are more convenient for pre-selection stage due to its classification characteristic. Further, decision methods for final selection are classified as linear weighting model, statistical models, artificial intelligence based models, mathematical programming models (Boer et al., 2001). The hybrid approaches derived by a combination of two different methods are also seen in the literature for solving the supplier selection problems. In some of these studies, firstly the suppliers were determined which are in accordance with enterprise needs and demands, then a mathematical programming was utilized in order to find out the optimum order quantity to be given to suppliers. In other studies, first importance degrees of criteria were calculated with a method, and then alternative suppliers were listed with another method (Onut et al., 2009). The studies carried out related with this subject were reviewed, while searching the literature due to this study is related to supplier selection in automotive industry, and an abstract was presented below.

The study done by Aksoy and Ozturk (2011), a supplier selection and evaluation based on artificial neural network was carried out in a firm operating in automotive industry and the alternative suppliers were classified as three groups as a result of this evaluation. Golmohammadi (2011) applied ANN (Artificial Neural Network) method to select the best one among the thirty one suppliers for eight products of a firm in automotive industry. Firstly, an artificial neural network model was designed depending on the managers' decisions for evaluating the supplier's performance then the supplier scores were obtained as a result of the application by redesigning the model by discussing inputs and outputs of the model. The suppliers were listed according to the supplier scores derived. Percin (2006), Kull and Talluri (2008) used AHP-GP (Goal Programming) approach for supplier selection in automotive industry. The AHP was utilized for calculation of weights of evaluation criteria and supplier selection was executed by transferring these weights into GP model. In the study of Kokangul and Susuz (2009), AHP and nonlinear integral programming methods were utilized for supplier selection work which carried out in a major automotive manufacturer. The AHP method was utilized for selecting the suppliers and calculating the weights of suppliers. The weights derived from AHP method were implemented as coefficients of objective function of proposed model and accordingly order quantities were calculated to be received by the suppliers. In the study of Shahanaghi and Yazdian (2009), the fuzzy TOPSIS method was utilized to select the best supplier according to the determined criteria, in purchasing major parts from alternative suppliers at the practice done in automotive enterprise and the best supplier was selected at the end of calculations made after three decision-makers have evaluated the four alternative suppliers according to the determined criteria. Boran et al., (2009), in their study, used fuzzy TOPSIS method for selection the most important supplier for a key part in the manufacturing process of a firm operating in automotive industry. In this study, determined four alternative suppliers depending on the selection criteria five alternative suppliers are evaluated by three DMs and at the end 
of this study the alternative suppliers were listed according to the closeness coefficient of the suppliers. Jolai et al., (2011), used TOPSIS and GP methods in order to select the best supplier and determine the order quantity, in a study carried out in the automotive manufacturing factory that wants to buy interior and exterior mirrors for three automotive models. The best supplier was selected by implementing fuzzy TOPSIS method in the study and the order quantity was determined by using the weights derived from fuzzy TOPSIS method in GP method. It was found that the results were consistently obtained from the study executed through sensitivity analyze at the end of the study. Zeydan et al., (2011), used fuzzy AHP-fuzzy TOPSIS-DEA methods in the study executed concerning to selection and evaluation of supplier in the automotive industry at Turkey. The fuzzy AHP method was applied for finding the weights of identified supplier selection criteria, by the weights obtained here were transferred into the fuzzy TOPSIS method then they obtained results were used in DEA method as an output, the supplier selection and evaluation was executed. Bevilacqua et al., (2006) presented a new method that transfers the typical quality function deployment approach (QFD) into the quality house in the supplier selection. Afterwards they used this method as fuzzy QFD in selecting suppliers of a company active in automotive industry and listed the alternative suppliers at the end of the study. In the study of Keskin et al., (2010), the fuzzy ART (Adaptive Resonance Theory) was used to select the convenient material supplier which supplies rod and ball joints to the automotive producing firm. Ten alternative suppliers were evaluated according to the criteria set out, by five decision-makers committee composed of quality, purchasing, manufacturing, finance departments and one group leader and at the end of this study the best suppliers were clustered categorically with their ranks. Based on the literature review, the studies which have included the criteria and methods used often in supplier selection of firms operating in automotive industry were presented in detail in Table 1.

Table 1

Supplier Selection Studies Performed in Automotive Industry

\begin{tabular}{|c|c|c|c|}
\hline Author(s) & Year & Method(s) & Supplier Selection Criteria \\
\hline Bevilacqua et al., & 2006 & Fuzzy QFD & $\begin{array}{l}\text { Experience in the industry, quality system certificate, response flexibility to customer } \\
\text { demands, financial condition, geographical location, the ability to manage online orders }\end{array}$ \\
\hline Percin & 2006 & AHP-GP & $\begin{array}{l}\text { Ability to manufacture, convenience quality, flexibility, delivery reliability, continuous } \\
\text { improvement programs, technical knowledge sharing, technological compatibility, product } \\
\text { innovation capability, organizational structure, reputation and position in the industry, } \\
\text { financial condition, management skills, performance history, geographical location, long } \\
\text { term relation, responding the complaints, communication systems, warranty support, repair } \\
\text { and maintenance service }\end{array}$ \\
\hline Kull and Talluri & 2008 & AHP-GP & $\begin{array}{l}\text { Cost, adequacy of documentation, timely delivery, company credibility, vehicle fleet, } \\
\text { follow-up after loading, dominance in the region, flexibility, service quality }\end{array}$ \\
\hline Boran et al., & 2009 & Fuzzy TOPSIS & $\begin{array}{l}\text { Quality of the product, compliance with the delivery date, compliance with the order } \\
\text { amount, compliance with the product specifications in the order, approach to the problems }\end{array}$ \\
\hline Kokangul and Susuz & 2009 & $\begin{array}{l}\text { AHP-Non-Linear Integer } \\
\text { Programming }\end{array}$ & ${ }^{\mathrm{r}}$ Cost, key quality characteristics, service \\
\hline Shahanaghi and Yazdian & 2009 & Fuzzy TOPSIS & Cost, references, product quality, delivery time, institutionalism, application time \\
\hline Keskin et al., & 2010 & Fuzzy ART & $\begin{array}{l}\text { Environmentalist process management, pollution control, environmental and legal } \\
\text { management, environmental costs, environmental image, environmental product }\end{array}$ \\
\hline Jolai et al. & 2011 & Fuzzy TOPSIS- GP & Business improvement, conformity side, quality, service, risks \\
\hline Aksoy and Ozturk & 2011 & ANN & $\begin{array}{l}\text { Delivery in time, affinity of the relation with its suppliers, product quality of the supplier, } \\
\text { technologic ability of the supplier, price/cost }\end{array}$ \\
\hline Zeydan et al., & 2011 & $\begin{array}{l}\text { Fuzzy AHP- Fuzzy } \\
\text { TOPSIS- DEA }\end{array}$ & Quality, on time delivery performance, geographical location, price \\
\hline Golmohammadi & 2011 & ANN & Economic factors, social factor, political situations \\
\hline
\end{tabular}

Upon examining the Table 1 , it is seen that the firms in automotive industry have used at most the criteria of cost/price, quality, delivery and flexibility in supplier selection studies. Furthermore, AHPGP, fuzzy TOPSIS and ANN have also been used in supplier selection studies. There have been various supplier selection methods available in the literature. According to the literature review in Table 1, it was found out that there is not any study which comprises together at the same time the methods of fuzzy TOPSIS and generalized Choquet integral (GCI). In this study, different from the existing literature, supplier selection will be performed through those fuzzy MCDM methods for the same supplier selection problem and the results obtained from two methods will be compared. The purpose of the use of cited methods individually in this study is to identify differences in the selection of 
suppliers through use of fuzzy TOPSIS method which is based on hierarchical structure and which, accordingly, does not consider the interaction among the criteria, GCI method which takes into account the interactions among the criteria. As such, the success of the selection process will increase. Fuzzy TOPSIS and generalized Choquet integral methods are briefly described in the following sub-headings.

\section{Fuzzy TOPSIS}

TOPSIS method is one of the MCDM methods frequently used in the selection of suppliers in literature (Chen \& Tsao, 2007). Fuzzy TOPSIS method, which has demonstrated very successful application examples at real world problems where personal judgments are expressed with linguistic data, can be utilized in making group decisions in fuzzy environments. The classical TOPSIS method is given superiority because the fuzzy TOPSIS method ensures freedom for expressing experts' thoughts in a certain range, as well as being a mathematical method handling the judgments of TOPSIS method experts with quantitative data (Chen, 2000). For detailed information regarding to sample applications and algorithmic steps of the fuzzy TOPSIS method; Chen et al. (2006), Boran et al. (2009), Zouggari and Benyoucef (2012) and Jolai et al. (2011) studies can be reviewed.

\section{Generalized Choquet integral}

Arithmetic averages and weighted averages can be used when the criteria are independent, so there is not any interaction between the criteria. The reason is because there is no method which allows modeling with these averages for the situations having interactions among the criteria. The weights are calculated with the aid of a non-aggregate cluster function when any interaction available among the criteria. In this situation, sub criteria of all criteria also have been weighted as well as each criterion (Grabisch \& Roubens, 2000). For that reason, it is more convenient to utilize the Choquet integral for being assessed of these criteria under the conditions of uncertainty and having interaction between the criteria (Yazgan et al., 2010; Grabisch \& Labreuche, 2008). The Choquet integral is a fuzzy integral which has a numerical structure used for evaluating the selection criteria by separating them into parts (Grabish \& Nicolas, 1994) and is a flexible collection operator which has the generalized structure of weighted average method (Tsai \& Lu, 2006). Meanwhile, the generalized Choquet integral is an extension of the standard Choquet integral (Tsai \& Lu, 2006; Demirel et al., 2010). The feature which distinguishes the standard Choquet integral from the generalized version is being real numbers of inputs and outputs (Tsai \& Lu, 2006). So the fuzzy criteria and measurable proofs are usually real numbers in the standard Choquet integral (Tsai \& Lu, 2006; Ming-Lang et al., 2009). For detailed information regarding to sample applications and algorithmic steps of the Generalized Choquet integral method; Tsai and Lu (2006) and Demirel et al. (2010) studies may be reviewed.

\section{The case study}

The supplier selection study with those fuzzy MCDM methods was carried out in a firm which operates in the automotive sector in Turkey. The manufacturing capacity of the firm is 125 thousand yearly. Averagely 22 vehicles are produced in an hour at the firm which has produced more than 600 thousand vehicles up to day and its daily total production arrives 400 pieces approximately. Models produced in Turkey, are being exported only from Turkey to over 60 countries including the Middle East and North Africa together with European countries such as especially Germany, France, Italy, Netherlands, the United Kingdom, Spain and Portugal.

The firm imports many components of the vehicles produced from abroad and especially from South Korea. It was decided to use the fuzzy TOPSIS and generalized Choquet integral methods individually in order to select the best among the alternative three suppliers (A, B, C) in South Korea where the steering gear box is supplied and used in vehicles produced in the scope of the study. The supplier selection model to be used in the application was created based on literature review were presented in 
detail in Table 1 and by considering the opinions of three expert DMs working in the purchasing department of the firm as in Fig. 1.

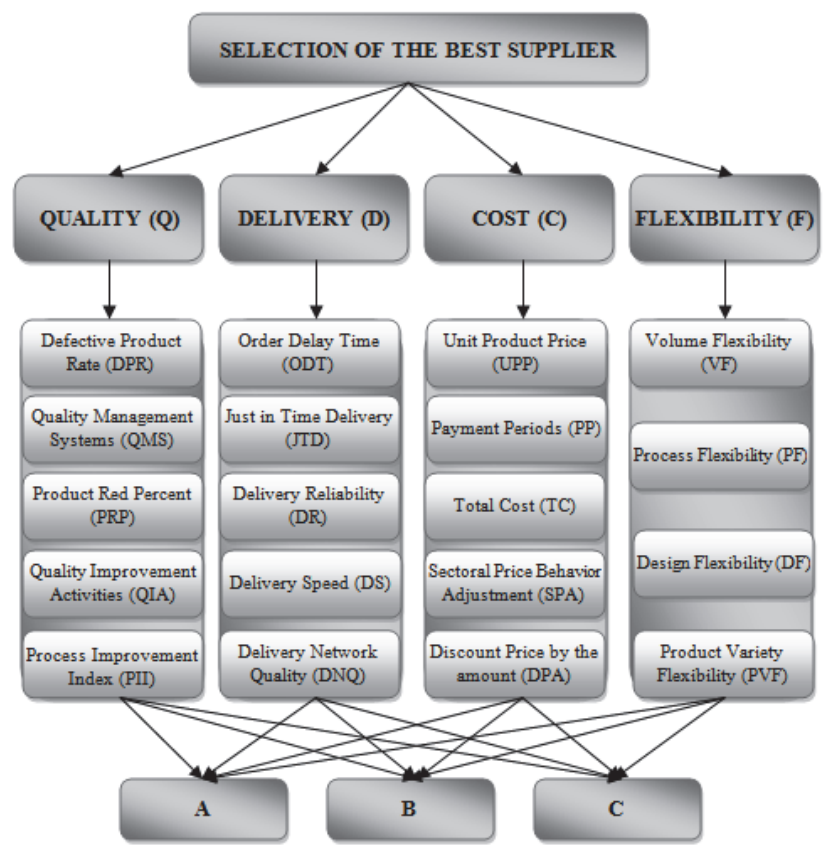

Fig. 1. Supplier Selection Model

\subsection{Application of Fuzzy TOPSIS Method in the Best Supplier Selection}

In this section, necessary calculations were performed for resolving the problem by using the steps of the fuzzy TOPSIS method algorithm of Chen (2000) for selecting the best among the three alternative suppliers determined by the firm. In this section, the study of Chen (2000) may be referred to obtain detailed information on algorithm concerning to the method, because only the results obtained via utilizing the method are given.

The alternative suppliers assessment forms, created as compatible with supplier selection model specified in Fig. 1 for supplier selection were filled out by the DMs. At this process, the DMs evaluated the importance weights of decision criteria used in supplier selection by utilizing linguistic variables given in Chen (2000) and the alternative suppliers according to the decision criteria. After the alternative suppliers have been assessed by the DMs, the importance weights were calculated which belong to main criteria by averaging assessments in the form of triangular fuzzy numbers of sub-criteria belong to each main criteria by the DMs for calculating the importance weights of main criteria and then given in Table 2 .

Table 2

Importance Weights of the Main Criteria

\begin{tabular}{lc}
\hline Main criteria & Importance weights $(\boldsymbol{l}, \boldsymbol{m}, \boldsymbol{u})$ \\
\hline Quality & $(0.293,0.447,0.613$ \\
Delivery & $(0.373,0.533,0.693)$ \\
Cost & $(0.327,0.500,0.680)$ \\
Flexibility & $(0.317,0.475,0.650)$ \\
\hline
\end{tabular}

The weighted normalized fuzzy decision matrix was generated with the aid of normalized fuzzy decision matrix and the table of importance weights of the criteria by considering that each decision 
criterion has different importance weights for the DMs. Here, weighted normalized fuzzy decision matrix as shown in Table 3 was obtained by multiplying, the values assigned to each alternative criterion in normalized fuzzy decision matrix, with importance weight of criterion at the column in which they present.

Table 3

The Weighted Normalized Fuzzy Decision Matrix

\begin{tabular}{lccc}
\hline & & ALTERNATIVES & C \\
\hline Criteria & A & B & $(0.151,0.344,0.613)$ \\
Quality & $(0.048,0.143,0.337)$ & $(0.057,0.184,0.422)$ & $(0.190,0.409,0.693)$ \\
Delivery & $(0.071,0.184,0.394)$ & $(0.093,0.244,0.490)$ & $(0.124,0.342,0.680)$ \\
Cost & $(0.043,0.125,0.333)$ & $(0.046,0.174,0.451)$ & $(0.196,0.397,0.650)$ \\
\hline
\end{tabular}

Afterwards Table 4 and Table 5 were created by calculating the distance of alternatives from fuzzy positive ideal solution (FPIS) $\left(d_{i}^{+}\right)$and the farness from fuzzy negative ideal solution (FNIS) $\left(d_{i}^{-}\right)$with the aid of vertex method.

Table 4

$d_{i}^{+}$Values for Every Criterion

\begin{tabular}{lccc}
\hline \multirow{2}{*}{ Criteria } & \multicolumn{1}{c}{$\boldsymbol{d}^{+}$} & $\mathbf{C}$ \\
\cline { 2 - 4 } & $\mathbf{A}$ & $\mathbf{B}$ & 0,658 \\
\hline Quality & 0,832 & 0,794 & 0,605 \\
Delivery & 0,795 & 0,743 & 0,659 \\
Cost & 0,842 & 0,795 & 0,615 \\
\hline
\end{tabular}

Table 5

$d_{i}^{-}$Values for Every Criterion

\begin{tabular}{lccc}
\hline \multirow{2}{*}{ Criteria } & \multicolumn{1}{c}{$\boldsymbol{d}_{\boldsymbol{i}}^{-}$} & $\mathbf{C}$ & \multicolumn{1}{c}{ B } \\
\cline { 2 - 4 } & $\mathbf{A}$ & 0,268 & 0,415 \\
Quality & 0,214 & 0,321 & 0,478 \\
Delivery & 0,255 & 0,280 & 0,445 \\
Cost & 0,207 & 0,331 & 0,454 \\
\hline
\end{tabular}

After calculating the distances, $d_{i}{ }^{+}$and $d_{i}{ }^{-}$distances are calculated for each criterion of each alternative were added up and closeness coefficients $\left(C C_{i}\right)$ were found for each alternative depending on these distances out and these results were presented in Table 6.

Table 6

$d_{i}^{+}, d_{i}^{-}$and $C C_{i}$ Values of Alternatives

\begin{tabular}{lccc}
\hline & \multicolumn{3}{c}{ ALTERNATIVES } \\
\cline { 2 - 4 } & $\mathbf{A}$ & $\mathbf{B}$ & $\mathbf{C}$ \\
\hline $\boldsymbol{d}_{\boldsymbol{i}}^{+}$ & 3,237 & 3,062 & 2,537 \\
$\boldsymbol{d}_{\boldsymbol{i}}$ & 0,960 & 1,200 & 1,792 \\
$\boldsymbol{C}_{\boldsymbol{i}}$ & 0,229 & 0,281 & $\mathbf{0 , 4 1 4}$ \\
\hline
\end{tabular}

It was understood that the supplier $C$ is the best supplier, the supplier $B$ is the second alternative and supplier $A$ is the alternative that may be preferred the last due to closeness coefficients are as $C C_{C}>C C_{B}>C C_{A}$ in descending order as a result of the evaluation carried out by the DMs according to the selection criteria of three alternative suppliers based on Table 6 . According to this result, it would be the best for the firm to choose supplier $C$ which has the highest closeness coefficient value among alternative suppliers. 


\subsection{Application of Generalized Choquet Integral Method in the Best Supplier Selection}

The alternative suppliers' performances will be assessed by following the steps available in algorithm structure of generalized Choquet integral on Tsai and $\mathrm{Lu}$ (2006) in this section. The studies of Tsai and Lu (2006) and Demirel et al. (2010) may be examined, for detailed algorithmic information related to the method, because only the tables would be presented concerning to derived results at supplier selection carried out through this method.

Step 1: The individual importance degrees of determined supplier selection criteria, tolerance interval of expected supplier performance and perceived supplier performance values were evaluated linguistically by three DMs in the firm according to the linguistic expressions given at Delgado et al., (1998) and an example of linguistic evaluation obtained the responses of the DM1 (Decision Maker 1) were presented in Table 7.

Table 7

Linguistic Expressions through the DM 1

\begin{tabular}{|c|c|c|c|c|c|c|c|c|c|c|c|c|}
\hline \multirow{2}{*}{ Criteria } & \multirow{2}{*}{$\begin{array}{l}\text { Individual } \\
\text { importance } \\
\text { of criteria }\end{array}$} & \multirow{2}{*}{$\begin{array}{l}\text { The } \\
\text { tolerance- } \\
\text { zone }\end{array}$} & \multicolumn{3}{|c|}{ Linguistic evaluation } & \multirow[t]{2}{*}{ Criteria } & \multirow{2}{*}{$\begin{array}{l}\text { Individual } \\
\text { importance } \\
\text { of criteria }\end{array}$} & \multirow{2}{*}{$\begin{array}{l}\text { The } \\
\text { tolerance } \\
\text { zone }\end{array}$} & \multicolumn{4}{|c|}{ Linguistic evaluation } \\
\hline & & & A & B & $\mathrm{C}$ & & & & A & B & $\mathrm{C}$ & \\
\hline$\overline{\mathrm{Q}}$ & $\mathrm{HI}$ & & & & & $\mathrm{C}$ & VI & & & & & \\
\hline$D P R$ & SI & {$[\mathrm{M}, \mathrm{SL}]$} & $\mathrm{M}$ & $\mathrm{SH}$ & SL & $U P P$ & HI & {$[\mathrm{SH}$,} & $\mathrm{VH}$ & SL & & SL \\
\hline$Q M S$ & SI & {$[\mathrm{SL}, \mathrm{SH}]$} & SL & SH & SH & $P P$ & SI & {$[\mathrm{M}, \mathrm{VH}]$} & SL & SH & & SH \\
\hline$P R P$ & $\mathrm{HI}$ & {$[\mathrm{SH}$} & SL & SL & $\mathrm{VH}$ & $T C$ & $\mathrm{HI}$ & {$[\mathrm{SL}, \mathrm{EH}]$} & SL & SL & & SH \\
\hline$Q I A$ & SI & {$[\mathrm{M}, \mathrm{VH}]$} & $\mathrm{VH}$ & SH & SH & $S P A$ & HI & {$[\mathrm{M}, \mathrm{VH}]$} & SH & SH & & M \\
\hline PII & HI & {$[\mathrm{SL}, \mathrm{SL}]$} & SL & SL & M & $D P A$ & HI & {$[\mathrm{L}, \mathrm{EH}]$} & $\mathrm{L}$ & SL & & SL \\
\hline$\overline{\mathrm{D}}$ & VI & & & & & $\overline{\mathrm{F}}$ & $\mathrm{HI}$ & & & & & \\
\hline$O D T$ & $\mathrm{M}$ & {$[\mathrm{SH}$,} & SH & $\mathrm{M}$ & SH & $V F$ & SI & {$[\mathrm{M}, \mathrm{SL}]$} & SL & $\mathrm{M}$ & & $\mathrm{SL}$ \\
\hline$J T D$ & HI & {$[\mathrm{SL}, \mathrm{EH}]$} & SL & M & SL & $P F$ & M & {$[\mathrm{SL}, \mathrm{SL}]$} & $\mathrm{M}$ & $\mathrm{M}$ & & SL \\
\hline$D R$ & SI & {$[\mathrm{M}, \mathrm{SL}]$} & SL & SL & SH & $D F$ & $\mathrm{HI}$ & {$[\mathrm{SL}, \mathrm{SH}]$} & M & SH & & SH \\
\hline$D S$ & SI & {$[\mathrm{SH}$,} & SH & SL & SH & $P V F$ & HI & {$[\mathrm{SL}, \mathrm{SL}]$} & SH & SH & & M \\
\hline$D N Q$ & M & {$[\mathrm{M}, \mathrm{VH}]$} & $\mathrm{VH}$ & SL & SL & & & & & & & \\
\hline
\end{tabular}

Step 2: The linguistic expressions obtained by the DM 1 were transformed into trapezoidal fuzzy numbers in Table 8 .

Table 8

Tolerance Zone of Expected Supplier Performance Transformed into Trapezoidal Fuzzy Numbers, Individual Importance Degrees and Perceived Supplier Performance

\begin{tabular}{|c|c|c|c|c|c|}
\hline \multirow{2}{*}{ Criteria } & \multirow{2}{*}{$\begin{array}{l}\text { Individual } \\
\text { importance of criteria }\end{array}$} & \multirow{2}{*}{$\begin{array}{l}\text { The combined tolerance } \\
\text { zone }\end{array}$} & \multicolumn{3}{|c|}{ Perceived nerformance levels of alternative supplier } \\
\hline & & & A & B & $\mathbf{C}$ \\
\hline$\overline{\mathbf{Q}}$ & $(0.72,0.78,0.92,0.97)$ & & & & \\
\hline$D P R$ & $(0.58,0.63,0.8,0.86)$ & {$[0.32,0.41,0.92,0.97]$} & $(0.32,0.41,0.58,0.65)$ & $(0.58,0.63,0.8,0.86)$ & $(0.72,0.78,0.92,0.97)$ \\
\hline$Q M S$ & $(0.58,0.63,0.8,0.86)$ & {$[0.17,0.22,0.8,0.86]$} & $(0.17,0.22,0.36,0.42)$ & $(0.58,0.63,0.8,0.86)$ & $(0.58,0.63,0.8,0.86)$ \\
\hline$P R P$ & $(0.72,0.78,0.92,0.97)$ & {$[0.58,0.63,0.98,1]$} & $(0.72,0.78,0.92,0.97)$ & $(0.72,0.78,0.92,0.97)$ & $(0.93,0.98,0.98,1)$ \\
\hline$Q I A$ & $(0.58,0.63,0.8,0.86)$ & {$[0.32,0.41,0.98,1]$} & $(0.93,0.98,0.98,1)$ & $(0.58,0.63,0.8,0.86)$ & $(0.58,0.63,0.8,0.86)$ \\
\hline$P I I$ & $(0.72,0.78,0.92,0.97)$ & {$[0.17,0.22,0.92,0.97]$} & $(0.72,0.78,0.92,0.97)$ & $(0.17,0.22,0.36,0.42)$ & $(0.32,0.41,0.58,0.65)$ \\
\hline$\overline{\mathbf{D}}$ & $(0.93,0.98,0.98,1)$ & & & & \\
\hline$O D T$ & $(0.32,0.41,0.58,0.65)$ & {$[0.58,0.63,1,1]$} & $(0.58,0.63,0.8,0.86)$ & $(0.32,0.41,0.58,0.65)$ & $(0.58,0.63,0.8,0.86)$ \\
\hline$J T D$ & $(0.72,0.78,0.92,0.97)$ & {$[0.17,0.22,1,1]$} & $(0.72,0.78,0.92,0.97)$ & $(0.32,0.41,0.58,0.65)$ & $(0.17,0.22,0.36,0.42)$ \\
\hline$D R$ & $(0.58,0.63,0.8,0.86)$ & {$[0.32,0.41,0.92,0.97]$} & $(0.72,0.78,0.92,0.97)$ & $(0.72,0.78,0.92,0.97)$ & $(0.58,0.63,0.8,0.86)$ \\
\hline$D S$ & $(0.58,0.63,0.8,0.86)$ & {$[0.58,0.63,1,1]$} & $(0.58,0.63,0.8,0.86)$ & $(0.72,0.78,0.92,0.97)$ & $(0.58,0.63,0.8,0.86)$ \\
\hline$D N Q$ & $(0.32,0.41,0.58,0.65)$ & {$[0.32,0.41,0.98,1]$} & $(0.93,0.98,0.98,1)$ & $(0.72,0.78,0.92,0.97)$ & $(0.72,0.78,0.92,0.97)$ \\
\hline$\overline{\mathrm{C}}$ & $(0.93,0.98,0.98,1)$ & & & & \\
\hline$U P P$ & $(0.72,0.78,0.92,0.97)$ & {$[0.58,0.63,0.98,1]$} & $(0.93,0.98,0.98,1)$ & $(0.72,0.78,0.92,0.97)$ & $(0.72,0.78,0.92,0.97)$ \\
\hline$P P$ & $(0.58,0.63,0.8,0.86)$ & {$[0.32,0.41,0.98,1]$} & $(0.72,0.78,0.92,0.97)$ & $(0.58,0.63,0.8,0.86)$ & $(0.58,0.63,0.8,0.86)$ \\
\hline$T C$ & $(0.72,0.78,0.92,0.97)$ & {$[0.72,0.78,1,1]$} & $(0.72,0.78,0.92,0.97)$ & $(0.72,0.78,0.92,0.97)$ & $(0.58,0.63,0.8,0.86)$ \\
\hline$S P A$ & $(0.72,0.78,0.92,0.97)$ & {$[0.32,0.41,0.98,1]$} & $(0.58,0.63,0.8,0.86)$ & $(0.58,0.63,0.8,0.86)$ & $(0.32,0.41,0.58,0.65)$ \\
\hline$D P A$ & $(0.72,0.78,0.92,0.97)$ & {$[0.04,0.1,1,1]$} & $(0.04,0.1,0.18,0.23)$ & $(0.72,0.78,0.92,0.97)$ & $(0.72,0.78,0.92,0.97)$ \\
\hline$\overline{\mathbf{F}}$ & $(0.72,0.78,0.92,0.97)$ & & & & \\
\hline$V F$ & $(0.58,0.63,0.8,0.86)$ & {$[0.32,0.41,0.92,0.97]$} & $(0.72,0.78,0.92,0.97)$ & $(0.32,0.41,0.58,0.65)$ & $(0.72,0.78,0.92,0.97)$ \\
\hline$P F$ & $(0.32,0.41,0.58,0.65)$ & {$[0.17,0.22,0.92,0.97]$} & $(0.32,0.41,0.58,0.65)$ & $(0.32,0.41,0.58,0.65)$ & $(0.17,0.22,0.36,0.42)$ \\
\hline$D F$ & $(0.72,0.78,0.92,0.97)$ & {$[0.17,0.22,0.8,0.86]$} & $(0.32,0.41,0.58,0.65)$ & $(0.58,0.63,0.8,0.86)$ & $(0.58,0.63,0.8,0.86)$ \\
\hline$P V F$ & $(0.72,0.78,0.92,0.97)$ & {$[0.17,0.22,0.92,0.97]$} & $(0.58,0.63,0.8,0.86)$ & $(0.58,0.63,0.8,0.86)$ & $(0.32,0.41,0.58,0.65)$ \\
\hline
\end{tabular}


Step 3: The results in Table 9 were obtained by averaging of individual importance degrees of the criteria assessed by three DMs, tolerance interval of expected supplier performance and perceived supplier performance.

Table 9

Average of Tolerance Interval of Expected Supplier Performance, Individual Importance Degrees and Perceived Supplier Performance Values

\begin{tabular}{|c|c|c|c|c|c|}
\hline \multirow{2}{*}{ Criteria } & \multirow{2}{*}{$\begin{array}{l}\text { Individual } \\
\text { importance of criteria }\end{array}$} & \multirow{2}{*}{$\begin{array}{l}\text { The combined tolerance } \\
\text { zone }\end{array}$} & \multicolumn{3}{|c|}{ Perceived performance levels of alternative supplier } \\
\hline & & & $\mathbf{A}$ & B & C \\
\hline Q & $(0.79,0.85,0.94,0.98)$ & & & & \\
\hline$D P R$ & $(0.74,0.8,0.9,0.94)$ & $(0.49,0.56,0.97,0.99)$ & $(0.73,0.79,0.85,0.88)$ & $(0.58,0.63,0.8,0.86)$ & $(0,72,0,78,0,92,0,97)$ \\
\hline$Q M S$ & $(0.67,0.73,0.88,0.93)$ & $(0.27,0.35,0.91,0.94)$ & $(0.54,0.59,0.73,0.79)$ & $(0.49,0.56,0.73,0.79)$ & $(0.49,0.56,0.73,0.79)$ \\
\hline$P R P$ & $(0.86,0.91,0.96,0.99)$ & $(0.49,0.54,0.99,1)$ & $(0.86,0.91,0.96,0.99)$ & $(0.67,0.73,0.88,0.93)$ & $(0.61,0.66,0.75,0.8)$ \\
\hline$Q I A$ & $(0.58,0.63,0.8,0.86)$ & $(0.22,0.28,0.94,0.98)$ & $(0.74,0.8,0.9,0.94)$ & $(0.49,0.56,0.73,0.79)$ & $(0.36,0.42,0.58,0.64)$ \\
\hline$P I I$ & $(0.88,0.92,0.97,0.99)$ & $(0.27,0.35,0.96,0.99)$ & $(0.74,0.8,0.9,0.94)$ & $(0.47,0.54,0.64,0.69)$ & $(0.49,0.56,0.73,0.79)$ \\
\hline D & $(0.86,0.91,0.96,0.99)$ & & & & \\
\hline$O D T$ & $(0.66,0.72,0.83,0.87)$ & $(0.58,0.63,0.99,1)$ & $(0.63,0.68,0.84,0.9)$ & $(0.54,0.61,0.77,0.83)$ & $(0.58,0.63,0.8,0.86)$ \\
\hline$J T D$ & $(0.72,0.78,0.92,0.97)$ & $(0.22,0.28,0.99,1)$ & $(0.49,0.54,0.69,0.75)$ & $(0.66,0.72,0.83,0.87)$ & $(0.36,0.42,0.58,0.64)$ \\
\hline$D R$ & $(0.74,0.8,0.9,0.94)$ & $(0.32,0.41,0.92,0.97)$ & $(0.45,0.53,0.69,0.76)$ & $(0.72,0.78,0.92,0.97)$ & $(0.54,0.61,0.77,0.83)$ \\
\hline$D S$ & $(0.81,0.86,0.92,0.95)$ & $(0.36,0.42,0.97,0.99)$ & $(0.49,0.56,0.73,0.79)$ & $(0.59,0.66,0.81,0.86)$ & $(0.36,0.42,0.58,0.64)$ \\
\hline$D N Q$ & $(0.68,0.73,0.83,0.87)$ & $(0.36,0.42,0.97,0.99)$ & $(0.86,0.91,0.96,0.99)$ & $(0.59,0.66,0.81,0.86)$ & $(0.54,0.59,0.73,0.79)$ \\
\hline $\mathrm{C}$ & $(0.74,0.8,0.9,0.94)$ & & & & \\
\hline$U P P$ & $(0.81,0.85,0.95,0.98)$ & $(0.58,0.63,0.99,1)$ & $(0.86,0.91,0.96,0.99)$ & $(0.63,0.68,0.84,0.9)$ & $(0.67,0.73,0.88,0.93)$ \\
\hline$P P$ & $(0.58,0.63,0.8,0.86)$ & $(0.32,0.41,0.98,1)$ & $(0.67,0.73,0.88,0.93)$ & $(0.49,0.56,0.73,0.79)$ & $(0.54,0.61,0.77,0.83)$ \\
\hline$T C$ & $(0.86,0.91,0.96,0.99)$ & $(0.54,0.59,0.93,0.95)$ & $(0.68,0.73,0.83,0.87)$ & $(0.74,0.8,0.9,0.94)$ & $(0.44,0.49,0.65,0.71)$ \\
\hline$S P A$ & $(0.72,0.78,0.92,0.97)$ & $(0.41,0.48,0.99,1)$ & $(0.63,0.68,0.84,0.9)$ & $(0.74,0.8,0.9,0.94)$ & $(0.61,0.67,0.79,0.84)$ \\
\hline$D P A$ & $(0.72,0.78,0.92,0.97)$ & $(0.54,0.61,0.97,0.99)$ & $(0.81,0.86,0.92,0.95)$ & $(0.72,0.78,0.92,0.97)$ & $(0.67,0.73,0.88,0.93)$ \\
\hline $\mathbf{F}$ & $(0.67,0.73,0.88,0.93)$ & & & & \\
\hline$V F$ & $(0.63,0.68,0.84,0.9)$ & $(0.23,0.31,0.88,0.93)$ & $(0.59,0.66,0.81,0.86)$ & $(0.45,0.53,0.69,0.76)$ & $(0.49,0.54,0.69,0.75)$ \\
\hline$P F$ & $(0.59,0.66,0.81,0.86)$ & $(0.18,0.24,0.94,0.98)$ & $(0.27,0.35,0.51,0.57)$ & $(0.49,0.56,0.73,0.79)$ & $(0.36,0.42,0.58,0.64)$ \\
\hline$D F$ & $(0.67,0.73,0.88,0.93)$ & $(0.17,0.22,0.88,0.93)$ & $(0.41,0.48,0.65,0.72)$ & $(0.49,0.56,0.73,0.79)$ & $(0.58,0.63,0.8,0.86)$ \\
\hline$P V F$ & $(0.63,0.68,0.84,0.9)$ & $(0.27,0.35,0.92,0.97)$ & $(0.63,0.68,0.84,0.9)$ & $(0.49,0.56,0.73,0.79)$ & $(0.45,0.53,0.69,0.76)$ \\
\hline
\end{tabular}

Step 4: The performance values belonging to three suppliers were normalized and here only the normalized values for $\alpha=0$ are given in Table 10 .

Table 10

The Assessment Results through Generalized Choquet Integral for $\alpha=0$

\begin{tabular}{|c|c|c|c|c|c|}
\hline \multirow{2}{*}{\multicolumn{2}{|c|}{ Criteria }} & \multirow{2}{*}{$\begin{array}{l}\text { Individual } \\
\text { importance of criteria }\end{array}$} & \multicolumn{3}{|c|}{ Normalized supplier performance } \\
\hline & & & $\mathbf{A}$ & B & C \\
\hline \multirow[t]{6}{*}{$\mathbf{Q}$} & & & {$[0.422,0.858]$} & {$[0.33,0.781]$} & {$[0.348,0.74]$} \\
\hline & $D P R$ & {$[0.74,0.94]$} & {$[0.368,0.695]$} & {$[0.295,0.683]$} & {$[0.365,0.738]$} \\
\hline & $Q M S$ & {$[0.67,0.93]$} & {$[0.297,0.758]$} & {$[0.275,0.76]$} & {$[0.275,0.76]$} \\
\hline & $P R P$ & {$[0.86,0.99]$} & {$[0.43,0.75]$} & {$[0.337,0.722]$} & {$[0.303,0.653]$} \\
\hline & $Q I A$ & {$[0.58,0.86]$} & {$[0.382,0.862]$} & {$[0.257,0.785]$} & {$[0.188,0.712]$} \\
\hline & PII & {$[0.88,0.99]$} & {$[0.377,0.837]$} & {$[0.242,0.71]$} & {$[0.252,0.76]$} \\
\hline \multirow[t]{6}{*}{ D } & & & {$[0.395,0.81]$} & {$[0.36,0.827]$} & {$[0.284,0.751]$} \\
\hline & $O D T$ & {$[0.66,0.87]$} & {$[0.313,0.658]$} & {$[0.27,0.623]$} & {$[0.29,0.64]$} \\
\hline & $J T D$ & {$[0.72,0.97]$} & {$[0.245,0.765]$} & {$[0.328,0.827]$} & {$[0.178,0.712]$} \\
\hline & $D R$ & {$[0.74,0.94]$} & {$[0.242,0.718]$} & {$[0.375,0.825]$} & {$[0.285,0.753]$} \\
\hline & $D S$ & {$[0.81,0.95]$} & {$[0.252,0.717]$} & {$[0.298,0.753]$} & {$[0.183,0.643]$} \\
\hline & $D N Q$ & {$[0.68,0.87]$} & {$[0.435,0.817]$} & {$[0.298,0.753]$} & {$[0.273,0.715]$} \\
\hline \multirow[t]{6}{*}{$\mathrm{C}$} & & & {$[0.424,0.798]$} & {$[0.391,0.767]$} & {$[0.34,0.748]$} \\
\hline & $U P P$ & {$[0.81,0.98]$} & {$[0.43,0.705]$} & {$[0.313,0.658]$} & {$[0.337,0.677]$} \\
\hline & $P P$ & {$[0.58,0.86]$} & {$[0.337,0.807]$} & {$[0.247,0.735]$} & {$[0.27,0.753]$} \\
\hline & $T C$ & {$[0.86,0.99]$} & {$[0.363,0.668]$} & {$[0.395,0.703]$} & {$[0.245,0.588]$} \\
\hline & $S P A$ & {$[0.72,0.97]$} & {$[0.313,0.745]$} & {$[0.372,0.768]$} & {$[0.305,0.715]$} \\
\hline & $D P A$ & {$[0.72,0.97]$} & {$[0.412,0.707]$} & {$[0.365,0.715]$} & {$[0.342,0.697]$} \\
\hline \multirow[t]{5}{*}{$\mathbf{F}$} & & & {$[0.313,0.817]$} & {$[0.274,0.809]$} & {$[0.303,0.839]$} \\
\hline & $V F$ & {$[0.63,0.9]$} & {$[0.327,0.818]$} & {$[0.26,0.765]$} & {$[0.278,0.762]$} \\
\hline & $P F$ & {$[0.59,0.86]$} & {$[0.145,0.698]$} & {$[0.257,0.807]$} & {$[0.188,0.733]$} \\
\hline & $D F$ & {$[0.67,0.93]$} & {$[0.237,0.775]$} & {$[0.28,0.81]$} & {$[0.323,0.845]$} \\
\hline & $P V F$ & {$[0.63,0.9]$} & {$[0.328,0.813]$} & {$[0.262,0.76]$} & {$[0.242,0.743]$} \\
\hline
\end{tabular}


Step 5: The supplier performance of main criteria was calculated by considering sub criteria and then meanwhile the performance values belonging to alternative suppliers were calculated. The fuzzy criteria and $\lambda$ values were calculated for $\alpha=0$ and $\alpha=1$.

Step 6: The alternative supplier performances were calculated by utilizing two-staged adding up process of generalized Choquet integral and then the defuzzified values belonging to all main criteria and sub criteria were calculated and these values were presented in Table 11.

\section{Table 11}

The Defuzzified Total Performance Values of Alternative Suppliers Utilizing Generalized Choquet Integral

\begin{tabular}{|c|c|c|c|c|c|c|}
\hline \multirow{2}{*}{ Criteria } & \multicolumn{3}{|c|}{ Supplier performance } & \multicolumn{3}{|c|}{ Defuzzified } \\
\hline & $\mathbf{A}$ & B & $\mathbf{C}$ & $\mathbf{A}$ & B & $\mathbf{C}$ \\
\hline $\begin{array}{l}\text { Overall supplier } \\
\text { value }\end{array}$ & $(0.422,0.459,0.799,0.816)$ & $(0.259,0.426,0.769,0.826)$ & $(0.339,0.389,0.767,0.698)$ & 0.624 & 0.570 & 0.548 \\
\hline$\overline{\mathbf{Q}}$ & $(0.422,0.46,0.802,0.858)$ & $(0.33,0.368,0.74,0.781)$ & $(0.348,0.392,0.69,0.74)$ & 0.635 & 0.555 & 0.542 \\
\hline$D P R$ & $(0.368,0.412,0.645,0.695)$ & $(0.295,0.332,0.622,0.683)$ & $(0.365,0.407,0.682,0.738)$ & 0.530 & 0.483 & 0.548 \\
\hline$Q M S$ & $(0.297,0.343,0.693,0.758)$ & $(0.275,0.325,0.69,0.76)$ & $(0.275,0.325,0.69,0.76)$ & 0.523 & 0.513 & 0.513 \\
\hline PRP & $(0.43,0.463,0.708,0.75)$ & $(0.337,0.372,0.668,0.722)$ & $(0.303,0.337,0.605,0.653)$ & 0.588 & 0.525 & 0.475 \\
\hline$Q I A$ & $(0.382,0.428,0.808,0.862)$ & $(0.257,0.308,0.722,0.785)$ & $(0.188,0.24,0.648,0.712)$ & 0.620 & 0.518 & 0.447 \\
\hline PII & $(0.377,0.418,0.777,0.837)$ & $(0.242,0.288,0.647,0.71)$ & $(0.252,0.298,0.69,0.76)$ & 0.602 & 0.472 & 0.500 \\
\hline$\overline{\mathbf{D}}$ & $(0.395,0.436,0.759,0.81)$ & $(0.36,0.417,0.77,0.827)$ & $(0.284,0.337,0.676,0.751)$ & 0.600 & 0.593 & 0.512 \\
\hline$O D T$ & $(0.313,0.347,0.605,0.658)$ & $(0.27,0.31,0.568,0.623)$ & $(0.29,0.322,0.585,0.64)$ & 0.481 & 0.443 & 0.459 \\
\hline$J T D$ & $(0.245,0.278,0.705,0.765)$ & $(0.328,0.368,0.772,0.827)$ & $(0.178,0.217,0.648,0.712)$ & 0.498 & 0.574 & 0.439 \\
\hline$D R$ & $(0.242,0.307,0.642,0.718)$ & $(0.375,0.43,0.755,0.825)$ & $(0.285,0.343,0.678,0.753)$ & 0.477 & 0.596 & 0.515 \\
\hline$D S$ & $(0.252,0.295,0.653,0.717)$ & $(0.298,0.345,0.693,0.753)$ & $(0.183,0.227,0.58,0.643)$ & 0.479 & 0.523 & 0.408 \\
\hline$D N Q$ & $(0.435,0.473,0.77,0.817)$ & $(0.298,0.345,0.693,0.753)$ & $(0.273,0.313,0.657,0.715)$ & 0.624 & 0.523 & 0.490 \\
\hline$\overline{\mathbf{C}}$ & $(0.424,0.459,0.734,0.798)$ & $(0.391,0.429,0.704,0.767)$ & $(0.34,0.378,0.673,0.748)$ & 0.604 & 0.573 & 0.535 \\
\hline$U P P$ & $(0.43,0.463,0.665,0.705)$ & $(0.313,0.347,0.605,0.658)$ & $(0.337,0.372,0.625,0.677)$ & 0.566 & 0.481 & 0.503 \\
\hline$P P$ & $(0.337,0.375,0.735,0.807)$ & $(0.247,0.288,0.658,0.735)$ & $(0.27,0.313,0.678,0.753)$ & 0.563 & 0.482 & 0.504 \\
\hline$T C$ & $(0.363,0.398,0.62,0.668)$ & $(0.395,0.432,0.653,0.703)$ & $(0.245,0.28,0.53,0.588)$ & 0.513 & 0.546 & 0.411 \\
\hline$S P A$ & $(0.313,0.347,0.678,0.745)$ & $(0.372,0.405,0.708,0.768)$ & $(0.305,0.343,0.652,0.715)$ & 0.521 & 0.563 & 0.504 \\
\hline$D P A$ & $(0.412,0.448,0.657,0.707)$ & $(0.365,0.407,0.657,0.715)$ & $(0.342,0.382,0.637,0.697)$ & 0.556 & 0.536 & 0.514 \\
\hline \multirow{5}{*}{$\begin{array}{c}V F \\
P F \\
D F \\
P V F\end{array}$} & $(0.313,0.376,0.748,0.817)$ & $(0.274,0.334,0.751,0.809)$ & $(0.303,0.36,0.778,0.839)$ & 0.564 & 0.542 & 0.570 \\
\hline & $(0.327,0.388,0.75,0.818)$ & $(0.26,0.327,0.693,0.765)$ & $(0.278,0.332,0.693,0.762)$ & 0.571 & 0.511 & 0.516 \\
\hline & $(0.145,0.203,0.632,0.698)$ & $(0.257,0.308,0.742,0.807)$ & $(0.188,0.24,0.668,0.733)$ & 0.420 & 0.528 & 0.458 \\
\hline & $(0.237,0.302,0.717,0.775)$ & $(0.28,0.338,0.753,0.81)$ & $(0.323,0.375,0.79,0.845)$ & 0.508 & 0.545 & 0.583 \\
\hline & $(0.328,0.38,0.747,0.813)$ & $(0.262,0.318,0.69,0.76)$ & $(0.242,0.307,0.673,0.743)$ & 0.567 & 0.508 & 0.491 \\
\hline
\end{tabular}

$A=0.624>B=0.570>C=0.548$ values were obtained when we look at general supplier performance at first, as a result of defuzzification values on Table 11 .

The supplier $A$ has been determined as the best supplier according to these values based on the total performance. While the supplier $B$ has been the best second alternative, the supplier $C$ has remained at the lowest level in terms of general performance.

Additionally, it demonstrates that supplier $A$ has appeared as the best alternative due to being the best of supplier $A$ in terms of quality, delivery and cost main criteria and supplier $A$ being the best second supplier at flexibility criteria. Being second of supplier $B$ in terms of quality, delivery and cost main criteria explain why this supplier took second place in the general ranking. Meanwhile, the supplier $C$ may be chosen only for the situations wherein flexibility criterion is important due to just being prominent at flexibility main criterion.

\section{Comparing the results}

Table 12 was obtained via the results derived by implementing each two methods individually at the supplier selection problem. 
Table 12

Comparing the Results of Fuzzy TOPSIS and Generalized Choquet Integral

\begin{tabular}{ccccc}
\hline & \multicolumn{2}{c}{ Fuzzy TOPSIS } & \multicolumn{2}{c}{ Generalized Choquet Integral } \\
\hline \multirow{2}{*}{ Supplier } & $\begin{array}{c}\text { Closeness } \\
\text { Coefficient }\end{array}$ & Ranking & $\begin{array}{c}\text { Defuzzified Overall Supplier } \\
\text { Value }\end{array}$ & Ranking \\
\hline & & & & \\
A & 0.229 & 3 & 0.624 & 1 \\
B & 0.281 & 2 & 0,570 & 3 \\
C & 0.414 & 1 & 0.548 & 3 \\
\hline
\end{tabular}

In Table 12, the values belonging to fuzzy TOPSIS express closeness coefficients, generalized Choquet integral values defuzzified total supplier performance. When the results are examined, the supplier $A$ takes the first place among alternatives at generalized Choquet integral methods, while the supplier $C$ takes the first place according to fuzzy TOPSIS method. The supplier $A$ which takes the first place may be chosen as the best supplier by taking into account of the application results of Generalized Choquet Integral method that considers interactions within criteria and among criteria dependencies, meanwhile the supplier $B$ may be chosen the best supplier which takes the second place according to the application results of generalized Choquet Integral and fuzzy TOPSIS methods.

At this point, it will be useful for the business to carry out the selection process in accordance with the results obtained from generalized Choquet integral method. This is because the precision of the results obtained increase interaction between criteria are taken into account in generalized Choquet integral methods. Furthermore, thanks to in generalized Choquet integral method performance values of all the main criteria and sub-criteria can be observed separately for each alternative supplier and thus selection process becomes much easier.

\section{Conclusion}

The business enterprises focus on their core proficiency activities in today's competitive world. Meanwhile at other activities, they struggle to maximize profits while minimizing production costs by supplying necessary products from other enterprises. For this purpose, the enterprises would like to work with suppliers which can offer services, to themselves, at quality levels requested, convenient in terms of cost and can be flexible with demand changes. To achieve this goal, it is quite important for the enterprises to select the most appropriate one among alternative suppliers. There are a lot of criteria and sub criteria which can be measured or not measured via strategic and organizational factors at supplier selection process. The traditional methods cannot introduce a realistic solution at this selection process due to supplier selection is a difficult decision problem necessitates all those criteria taken into account. However, MCDM methods facilitate the solving to some extent and allow the DMs to correct decisions.

The fuzzy TOPSIS method, which is one of the MCDM methods and utilized in making group decisions in fuzzy environments, facilitates more precise and more reliable selections among the alternatives by DMs enabling them to assign different importance weights to decision criteria. The generalized Choquet integral is a method which produces very successful results and being utilized in decision making problems where in interactions are available between the ambiguity and decision criteria.

In this study, the fuzzy TOPSIS and the generalized Choquet integral are used individually in order to select the best one among three alternative suppliers doing business in South Korea, where the steering gear box product supplied from that is used in vehicles produced by a large-scale firm present in automotive industry in Turkey. 
The supplier $C$ took the first place with the closeness coefficient as 0.414 according to the results derived from the fuzzy TOPSIS method. It is seen that the delivery (D) criterion has the highest importance weight when looked at importance weights of the criteria.

The supplier $A$ took the first place among the alternative suppliers with its 0.624 total performance value, according to total performance of the suppliers, upon based on the application results of generalized Choquet integral method. This result is supported by being high of the performance values of the supplier $A$ 's criteria such as quality (Q), cost (C) and delivery (D) among its main criteria upon compared to main criteria values of other alternatives. The highest performance value was possessed by the quality (Q) criterion among the main criteria and by the delivery network quality (DNQ) criterion which is a sub-criterion of the delivery (D) criterion among the sub-criteria according to the other results derived from this method.

The supplier $A$ according to generalized Choquet integral methods, and the supplier $C$ according to the fuzzy TOPSIS method took the first places, upon comparing the results derived from the two methods. Being taken the first place by the supplier $A$ at the generalized Choquet Integral methods, is consistent with the fact that this method has been taking into account the interaction between criteria, Consequently, it is the best for the business firm where the application carried out, to choose the supplier $A$ who taking the first place at the generalized Choquet integral method which considering interaction within criteria and between criteria dependencies, and to prefer supplier $B$ who taking the second place at the fuzzy TOPSIS and generalized Choquet integral methods as being the second alternative.

This executed study, has quite a significance in point of the contribution has been provided to the literature in terms of being the first study wherein both the generalized Choquet Integral has been used at supplier selection problems in automotive industry, and in terms of has been implemented individually at the supplier selection problem of the two methods.

\section{References}

Aksoy, A., \& Öztürk, N. (2011). Supplier selection and performance evaluation in just-in-time production environments. Expert systems with applications, 38(5), 6351-6359.

Amid, A., Ghodsypour, S. H., \& O’Brien, C. (2006). Fuzzy multiobjective linear model for supplier selection in a supply chain. International Journal of Production Economics, 104(2), 394-407.

Araz, C., \& Ozkarahan, I. (2007). Supplier evaluation and management system for strategic sourcing based on a new multicriteria sorting procedure. International journal of production economics, 106(2), 585-606.

Benyoucef, L., Ding, H., \& Xie, X. (2003). Supplier selection problem: Selection criteria and methods. INRIA, Rapport Dereche reche, no 4726.

Bevilacqua, M., Ciarapica, F. E., \& Giacchetta, G. (2006). A fuzzy-QFD approach to supplier selection. Journal of Purchasing and Supply Management, 12(1), 14-27.

De Boer, L., Labro, E., \& Morlacchi, P. (2001). A review of methods supporting supplier selection. European journal of purchasing \& supply management, 7(2), 75-89.

Boran, F. E., Genç, S., Kurt, M., \& Akay, D. (2009). A multi-criteria intuitionistic fuzzy group decision making for supplier selection with TOPSIS method. Expert Systems with Applications, 36(8), 11363 11368.

Byun, T., Oh, J., \& Jeong, B. (2014). Analysis of supply chain network by rules of origin in FTA environment. International Journal of Industrial Engineering: Theory, Applications and Practice, 21(6). 421-435.

Chen, C. F., \& Tsai, D. (2007). How destination image and evaluative factors affect behavioral intentions?. Tourism management, 28(4), 1115-1122. 
Chen, C. T. (2000). Extensions of the TOPSIS for group decision-making under fuzzy environment. Fuzzy sets and systems, 114(1), 1-9.

Chen, C. T., Lin, C. T., \& Huang, S. F. (2006). A fuzzy approach for supplier evaluation and selection in supply chain management. International journal of production economics, 102(2), 289-301.

Childerhouse, P., Luo, W., Basnet, C., Ahn, H. J., Lee, H., \& Vossen, G. (2013). Evolution of interfirm relationships: A study of supplier-logistical services provider-customer triads. International Journal of Industrial Engineering: Theory, Applications and Practice, 20, 126-140.

Delgado, M., Herrera, F., Herrera-Viedma, E., \& Martínez, L. (1998). Combining numerical and linguistic information in group decision making. Information Sciences, 107(1), 177-194.

Demirel, T., Demirel, N. Ç., \& Kahraman, C. (2010). Multi-criteria warehouse location selection using Choquet integral. Expert Systems with Applications, 37(5), 3943-3952.

Faez, F., Ghodsypour, S. H., \& O’brien, C. (2009). Vendor selection and order allocation using an integrated fuzzy case-based reasoning and mathematical programming model. International Journal of Production Economics, 121(2), 395-408.

Ghodsypour, S. H., \& O'Brien, C. (1998). A decision support system for supplier selection using an integrated analytic hierarchy process and linear programming. International journal of production economics, 56, 199-212.

Golmohammadi, D. (2011). Neural network application for fuzzy multi-criteria decision making problems. International Journal of Production Economics, 131(2), 490-504.

Grabisch, M., \& Labreuche, C. (2010). A decade of application of the Choquet and Sugeno integrals in multi-criteria decision aid. Annals of Operations Research, 175(1), 247-286.

Grabisch, M., \& Nicolas, J. M. (1994). Classification by fuzzy integral: performance and tests. Fuzzy sets and systems, 65(2-3), 255-271.

Grabisch, M., \& Roubens, M. (2000). Application of the Choquet integral in multicriteria decision making. Fuzzy Measures and Integrals-Theory and Applications, 348-374.

Ho, W., Xu, X., \& Dey, P. K. (2010). Multi-criteria decision making approaches for supplier evaluation and selection: A literature review. European Journal of Operational Research, 202(1), 16-24.

Hong, K. S., \& Lee, C. (2013). Optimal pricing and guaranteed lead time with lateness penalties. International Journal of Industrial Engineering: Theory, Applications and Practice, 20, 153-162.

Jolai, F., Yazdian, S. A., Shahanaghi, K., \& Khojasteh, M. A. (2011). Integrating fuzzy TOPSIS and multi-period goal programming for purchasing multiple products from multiple suppliers. Journal of Purchasing and Supply Management, 17(1), 42-53.

Keskin, G. A., İlhan, S., \& Özkan, C. (2010). The Fuzzy ART algorithm: A categorization method for supplier evaluation and selection. Expert Systems with Applications, 37(2), 1235-1240.

Kokangul, A., \& Susuz, Z. (2009). Integrated analytical hierarch process and mathematical programming to supplier selection problem with quantity discount. Applied mathematical modelling, 33(3), 1417-1429.

Kull, T. J., \& Talluri, S. (2008). A supply risk reduction model using integrated multicriteria decision making. IEEE Transactions on Engineering Management, 55(3), 409-419.

Liu, F. H. F., \& Hai, H. L. (2005). The voting analytic hierarchy process method for selecting supplier. International Journal of Production Economics, 97(3), 308-317.

Metz, P.J. (1998). Demystifying supply chain management. Supply Chain Management Review, 2(4), $1-10$.

Tseng, M. L., Chiang, J. H., \& Lan, L. W. (2009). Selection of optimal supplier in supply chain management strategy with analytic network process and choquet integral. Computers \& Industrial Engineering, 57(1), 330-340.

Muralidharan, C., Anantharaman, N., \& Deshmukh, S. G. (2002). A multi-criteria group decisionmaking model for supplier rating. Journal of supply chain management, 38(4), 22.

Önüt, S., Kara, S. S., \& Işik, E. (2009). Long term supplier selection using a combined fuzzy MCDM approach: A case study for a telecommunication company. Expert Systems with Applications, 36(2), 3887-3895. 
Perçin, S. (2006). An application of the integrated AHP-PGP model in supplier selection. Measuring Business Excellence, 10(4), 34-49.

Shahanaghi, K., \& Yazdian, S. A. (2009). Vendor selection using a new fuzzy group TOPSIS approach. Journal of Uncertain Systems, 3(3), 221-231.

Soner, S., \& Önüt, S. (2006). Multi-criteria supplier selection: An ELECTRE-AHP application. Sigma, 4, 110-120.

Tam, M. C., \& Tummala, V. R. (2001). An application of the AHP in vendor selection of a telecommunications system. Omega, 29(2), 171-182.

Tsai, H. H., \& Lu, I. Y. (2006). The evaluation of service quality using generalized Choquet integral. Information Sciences, 176(6), 640-663.

Yazgan, H. R., Boran, S., \& Goztepe, K. (2010). Selection of dispatching rules in FMS: ANP model based on BOCR with choquet integral. The International Journal of Advanced Manufacturing Technology, 49(5-8), 785-801.

Zeydan, M., Çolpan, C., \& Çobanoğlu, C. (2011). A combined methodology for supplier selection and performance evaluation. Expert Systems with Applications, 38(3), 2741-2751.

Zouggari, A., \& Benyoucef, L. (2012). Simulation based fuzzy TOPSIS approach for group multicriteria supplier selection problem. Engineering Applications of Artificial Intelligence, 25(3), 507519.

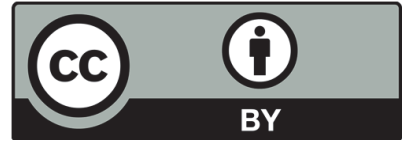

(C) 2016 by the authors; licensee Growing Science, Canada. This is an open access article distributed under the terms and conditions of the Creative Commons Attribution (CC-BY) license (http://creativecommons.org/licenses/by/4.0/). 